\title{
Geographic distribution of archaeological sites and their response to climate and environmental change between 10.0-2.8 ka BP in the Poyang Lake Basin, China
}

\author{
XU Jiajia ${ }^{1,2}$, "JIA Yulian², MA Chunmei ${ }^{1},{ }^{*}$ ZHU Cheng ${ }^{1}$, WU Li ${ }^{3}$, LI Yuyuan ${ }^{4}$, \\ WANG Xinhao ${ }^{5}$ \\ 1. School of Geographic and Oceanographic Sciences, Nanjing University, Nanjing 210046, China; \\ 2. Key Laboratory of Poyang Lake Wetland and Watershed Research, Ministry of Education; School of Geog- \\ raphy and Environment, Jiangxi Normal University, Nanchang 330022, China; \\ 3. College of Territorial Resources and Tourism, Anhui Normal University, Wuhu 241002, Anhui, China; \\ 4. Jiangxi Provincial Institute of Cultural Relics and Archaeology, Nanchang 330003, China; \\ 5. College of Hydrology and Water Resources, Hohai University, Nanjing 210098, China
}

\begin{abstract}
The temporal-spatial geographic distribution of archaeological sites and its feature between 10.0-2.8 ka BP ( $\mathrm{ka} \mathrm{BP}=$ thousands of years before $0 \mathrm{BP}$, where " $0 \mathrm{BP}$ " is defined as the year AD 1950) were determined, based on GIS spatial analysis in the Poyang Lake Basin. The relationship between geographic distribution of sites of different periods under subsistence existence of ancient civilizations, climate and environmental change was investigated. The results revealed numerous archaeological sites of the Neolithic Age (10.0-3.6 ka BP). The sites were mainly located in the northern part of the Poyang Lake Basin, a hilly and mountainous area with many river terraces suitable for the development of human civilization. The number of archaeological sites rapidly increased during the Shang and Zhou dynasties (3.6-2.8 ka BP) and spread widely on the floodplains of the middle and lower reaches of Ganjiang River and onto the west, south, and southeast beach areas of the Poyang Lake. Holocene records of climate change suggested that it was possible that climate fluctuations had a great impact on human evolution in the study area. Before 3.6 ka BP, westward and northward expansion of Neolithic cultures in the Poyang Lake watershed occurred under the background of climate amelioration (becoming warmer and wetter). The ancient people lived in the hilly areas with high elevation. The simple mode of a fishing and gathering economy was mostly suited to this area in the early Neolithic Age. The scope of human activities was expanded and cultural diversity developed in the late Neolithic Age. However, with population growth and increasing survival pressure in a dry-cold climatic stage after 3.6 ka BP, this sim-
\end{abstract}

Received: 2015-08-28 Accepted: 2016-01-06

Foundation: National Natural Science Foundation of China, No.41371204, No.41571179; Major Program of the National Social Science Foundation of China, No.11\&ZD183; The Collaborative Innovation Center for Major Ecological Security Issues of Jiangxi Province and Monitoring Implementation, No.JXS-EW-00

Author: Xu Jiajia, PhD Candidate, specialized in environmental archaeology. E-mail: jjiaxu@163.com

"Corresponding author: Jia Yulian (1971-), Professor, E-mail: northforest@sohu.com Zhu Cheng (1954-), Professor, E-mail: zhuchengnj@126.com 
ple living mode had to be abandoned, and various forms of economy, the majority being agriculture, were developed on flood plains of the lower reaches of numerous rivers around Poyang Lake. This promoted flourishing of the Bronze culture of South China.

Keywords: Poyang Lake Basin; archaeological sites; temporal-spatial distribution; climate and environmental change; Shang and Zhou dynasties

\section{Introduction}

Environmental archaeology has been developing rapidly as a cross-discipline during the past decade, largely spurred by the advance of research in Quaternary geology, archaeology, and palynology (Evans et al., 2014; Oonk and Spijker, 2015; Mayle and Iriarte, 2014; Grahn et al., 2013; Innes et al., 2014; Xu et al., 2015). This has promoted research of the relationship between palaeoenvironmental changes and regional ancient cultures (Haug et al., 2003; Kuper and Kropelin, 2006; Oinonen et al., 2014). During prehistoric times of relatively low productivity, human ancestors relied heavily on the physical environment. Therefore, climate change may have exerted great impact on the evolution of regional ancient cultures by affecting living conditions and natural resources. Using data on temporal-spatial distribution of archaeological sites of cultures on a regional/sub-regional scale and records of climate change may be an effective way to study human-environment interactions, especially in arid and subarid northern China and flood plain areas of the Yangtze River (Guo et al., 2013; 2014; Gao et al., 2009; Wu et al., 2011; Li et al., 2013; Li et al., 2014; Zhu et al., 2014). Both of these areas are sensitive to summer monsoonal climate change in East Asia (Zhang et al., 2011; Chen et al., 2015a, 2015b; Xie et al., 2013; Liu et al., 2014; Zhang et al., 2013; Wu et al., 2012).

The Poyang Lake Basin, located in the middle reaches of the Yangtze River, enjoyed a splendid ancient culture during the late Holocene (Liu, 2000), as did other parts of the Yangtze River Basin (Duan, 2003; Sun and Gao, 2006; Chen, 2005). The Xianrendong cave site and the Diaotonghuan site of the early Neolithic period may be the earliest ruins of paleo-rice and pottery in East Asia known at present, suggesting that this catchment may be one source of Chinese rice agriculture (Peng and Zhou, 2004). Development of the Neolithic cultures was slow during the middle Neolithic stage; however, during this stage, diverse cultural types emerged and speeded up steadily toward the late Neolithic stage. The Shang and Zhou dynasties in the Poyang Lake Basin flourished as the best-developed Bronze culture in South China (Liu, 1993; Long et al., 1992; Xu, 1987). Present-day environmental archaeological investigation has been intensively conducted in the Yangtze River basin (Zhu et al., 2005; 2007; Zheng et al., 2008; Zhu et al., 2005a; Li et al., 2013; Wu et al., 2014a, 2014b). However, because the Poyang Lake Basin is mountainous, how were the archaeological sites distributed geographically, and what was their response to climate and environmental change from $10.0-2.8 \mathrm{ka}$ BP? This study focuses on analyzing distribution and evolution of culture to clarify the relationship between subsistence models of ancient inhabitants and Holocene climate change.

\section{Study area}

The Poyang Lake, with an area of $3100 \mathrm{~km}^{2}$ and at an elevation of $18.4 \mathrm{~m}$ (Yellow Sea ele- 
vation system) is the largest fresh water lake in China (Figure 1). Its catchment has an area of 162.200 $\mathrm{km}^{2}$, accounting for nearly $97 \%$ of the entire area of Jiangxi Province. The dustpan-like basin is surrounded by high mountains except for the north side, which slopes gradually downward from the south, to the north at Poyang Lake beach, with the lowest elevation of $15 \mathrm{~m}$. Five large rivers, Xiuhe River, Ganjiang River, Fuhe River, Xinjiang River, and Raohe River, flow into Poyang Lake. Water flows from the lake into the Yangtze River through Lake Mouth (Hukou). This hydrological pattern constitutes the relatively complete Poyang Lake water system (Qiu et al., 2006).

The climate of the region is humid subtropical and is strongly influenced by the East Asian Mon-

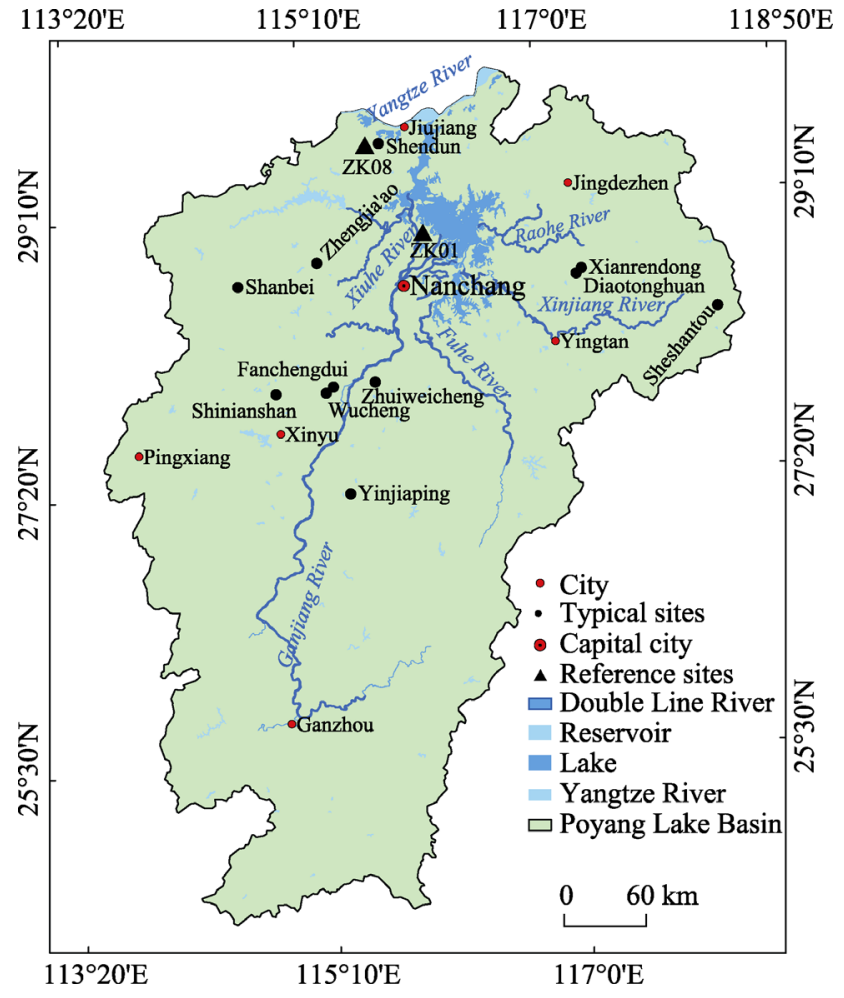

Figure 1 Sketch map of the location of the entire Poyang Lake Basin showing the water systems and major cities soon regime (summer monsoon and winter monsoon included). The mean annual temperature is approximately $17-20^{\circ} \mathrm{C}$, with July mean temperatures of $29-32^{\circ} \mathrm{C}$ and January mean temperatures of $3.0-5.0^{\circ} \mathrm{C}$. Annual precipitation is approximately $1300-1900 \mathrm{~mm}$, most of which falls between April and September as the summer monsoon intensifies.

\section{Materials and methods}

The essential materials used for developing a distribution map of archaeological sites include two spatial data sources: one is a Digital Elevation Model (DEM), with a resolution of $90 \mathrm{~m} \times 90 \mathrm{~m}$ downloaded from the International Scientific Data Service Platform; the other is the position data of archaeological sites, mainly provided by Jiangxi Provincial Institute of Cultural Relics and Archaeology and others from reports and published papers on archaeological excavation. Totally, there are 597 archaeological sites from the Neolithic Age and the Shang and Zhou dynasties in the Poyang Lake Basin, with 110 Neolithic Age sites and 487 sites from the Shang and Zhou dynasties. Based on chronological sequences (Peng, 1981a, 1981b; Li, 1982; Li et al., 1986a, 1986b; Xiao, 1991; Liu, 1993; Zhong, 2007), these archaeological sites are classified into four groups: early Neolithic Age (10-8.0 ka BP), including the Xianrendong culture; middle Neolithic Age (8.0-4.8 ka BP), including the Shinianshan culture, Zhengjia'ao culture, and Shanbei culture; late Neolithic Age (4.8-3.6 ka BP), including the Zhuweicheng-Fanchengdui culture and Sheshantou culture; Shang and Zhou dynasties (3.6-2.8 ka BP), including the Wucheng culture and Wannian culture (see 
Table 1).

All of the Neolithic cultural sites and the Shang and Zhou dynasties cultural sites referred to in this paper were plotted on the relief map. The mapping steps were as follows: manual registration of the topographic and drainage map, 90-m resolution DEM data and sites of different periods of the Poyang Lake Basin were implemented and digitalized using ArcGIS first; then distribution maps of cultural sites were plotted on the relief map of different elevation layers and colours (Figure 2). Finally, the relationship between human activity and climate change from the Neolithic Age to the Shang and Zhou dynasties in the study area was analyzed.

Table 1 Radiocarbon and thermoluminescence ages of archaeological sites used in this study from the Poyang Lake Basin

\begin{tabular}{|c|c|c|c|c|c|c|c|}
\hline No. & Name of site & $\begin{array}{l}\text { Archaeological age } \\
\text { (determined by } \\
\text { excavated relics) }\end{array}$ & $\begin{array}{c}\text { Materials } \\
\text { dated }\end{array}$ & $\begin{array}{l}\text { Dating } \\
\text { methods }\end{array}$ & Lab.ID & $\begin{array}{l}\text { Dating results } \\
\text { (a BP) }\end{array}$ & Reference \\
\hline \multirow[t]{6}{*}{1} & Xianrendong & $\begin{array}{l}\text { Xianrendong Stage } \\
(10.0-8.0 \mathrm{ka} \mathrm{BP})\end{array}$ & $\begin{array}{l}\text { Clamshell } \\
\text { fragments }\end{array}$ & ${ }^{14} \mathrm{C}$ & ZK-39 & $10870 \pm 24$ & $\begin{array}{l}\text { The Institute of } \\
\text { Archaeology, }\end{array}$ \\
\hline & & & & & & & CASS (1974) \\
\hline & Xianrendong & & Animal bones & ${ }^{14} \mathrm{C}$ & ZK-92-0 & $8825 \pm 240$ & $\begin{array}{l}\text { The Institute of } \\
\text { Archaeology, } \\
\text { CASS (1977) }\end{array}$ \\
\hline & Xianrendong & & Pottery shard & $\mathrm{TL}$ & WX01 & $10900 \pm 1000$ & Wu et al. (2005) \\
\hline & Xianrendong & & Pottery shard & TL & WX02 & $11700 \pm 1000$ & Wu et al. (2005) \\
\hline & Xianrendong & & Pottery shard & TL & WX09 & $7850 \pm 700$ & Wu et al. (2005) \\
\hline \multirow[t]{2}{*}{2} & Shinianshan & $\begin{array}{l}\text { Shinianshan Stage } \\
(8.0-4.5 \mathrm{ka} \mathrm{BP})\end{array}$ & Peat & ${ }^{14} \mathrm{C}$ & & $5768 \pm 178$ & JPICRA (1991) \\
\hline & Shinianshan & & Wood charcoal & ${ }^{14} \mathrm{C}$ & BK89089 & $4500 \pm 100$ & Xu (1996) \\
\hline 3 & Zhengjia'ao & $\begin{array}{l}\text { Zhengjia'ao Stage } \\
(5.5-5.0 \mathrm{ka} \text { BP })\end{array}$ & & & & $5500-5000$ & JPICRA (1989) \\
\hline 4 & Shanbei & $\begin{array}{l}\text { Shanbei Stage } \\
(5.0-4.8 \mathrm{ka} \mathrm{BP})\end{array}$ & Wood charcoal & ${ }^{14} \mathrm{C}$ & & $4980 \pm 331$ & $\begin{array}{l}\text { Xiao (1991); } \\
\text { Tang (1996) }\end{array}$ \\
\hline 5 & Zhuweicheng & $\begin{array}{l}\text { Zhuweicheng- } \\
\text { Fanchengdui Stage } \\
(4.8-4.0 \mathrm{ka} \mathrm{BP})\end{array}$ & & & & $4600-4100$ & $\begin{array}{l}\text { Tang (1996); } \\
\text { Li et al. }(1986)\end{array}$ \\
\hline 6 & Fanchengdui & & & & & $5000-4000$ & Cao (1993) \\
\hline 7 & Sheshantou & $\begin{array}{l}\text { Sheshantou Stage } \\
(4.5-3.7 \mathrm{ka} \mathrm{BP})\end{array}$ & & & & $4500-3700$ & JPICRA (1997) \\
\hline \multirow[t]{2}{*}{8} & Wucheng & $\begin{array}{l}\text { Wucheng Stage } \\
(3.6-2.8 \mathrm{ka} \mathrm{BP})\end{array}$ & $\begin{array}{l}\text { Bamboo } \\
\text { charcoal }\end{array}$ & ${ }^{14} \mathrm{C}$ & ZK-447 & $3345 \pm 90$ & $\begin{array}{l}\text { The Institute of } \\
\text { Archaeology, } \\
\text { CASS (1979) }\end{array}$ \\
\hline & & & Wood charcoal & ${ }^{14} \mathrm{C}$ & ZK-446 & $3480 \pm 150$ & $\begin{array}{l}\text { The Institute of } \\
\text { Archaeology, } \\
\text { CASS (1979) }\end{array}$ \\
\hline \multirow[t]{3}{*}{9} & Dayangzhou & & & ${ }^{14} \mathrm{C}$ & & $3620 \pm 140$ & Peng (2004) \\
\hline & & & & ${ }^{14} \mathrm{C}$ & & $3110 \pm 330$ & Peng (2004) \\
\hline & & & & ${ }^{14} \mathrm{C}$ & & $3360 \pm 160$ & Peng (2004) \\
\hline 10 & Shendun & & Wood charcoal & ${ }^{14} \mathrm{C}$ & & $3360 \pm 100$ & Li et al. (1986 b) \\
\hline 11 & Shazhou & & Wood & ${ }^{14} \mathrm{C}$ & ZK-2514 & $2960 \pm 320$ & $\begin{array}{l}\text { The Institute of } \\
\text { Archaeology, } \\
\text { CASS (1991) }\end{array}$ \\
\hline 12 & Wannian & $\begin{array}{l}\text { Wannian Stage } \\
(3.5-2.7 \mathrm{ka} \mathrm{BP})\end{array}$ & & & & $3500-2700$ & Zhao (2009) \\
\hline
\end{tabular}



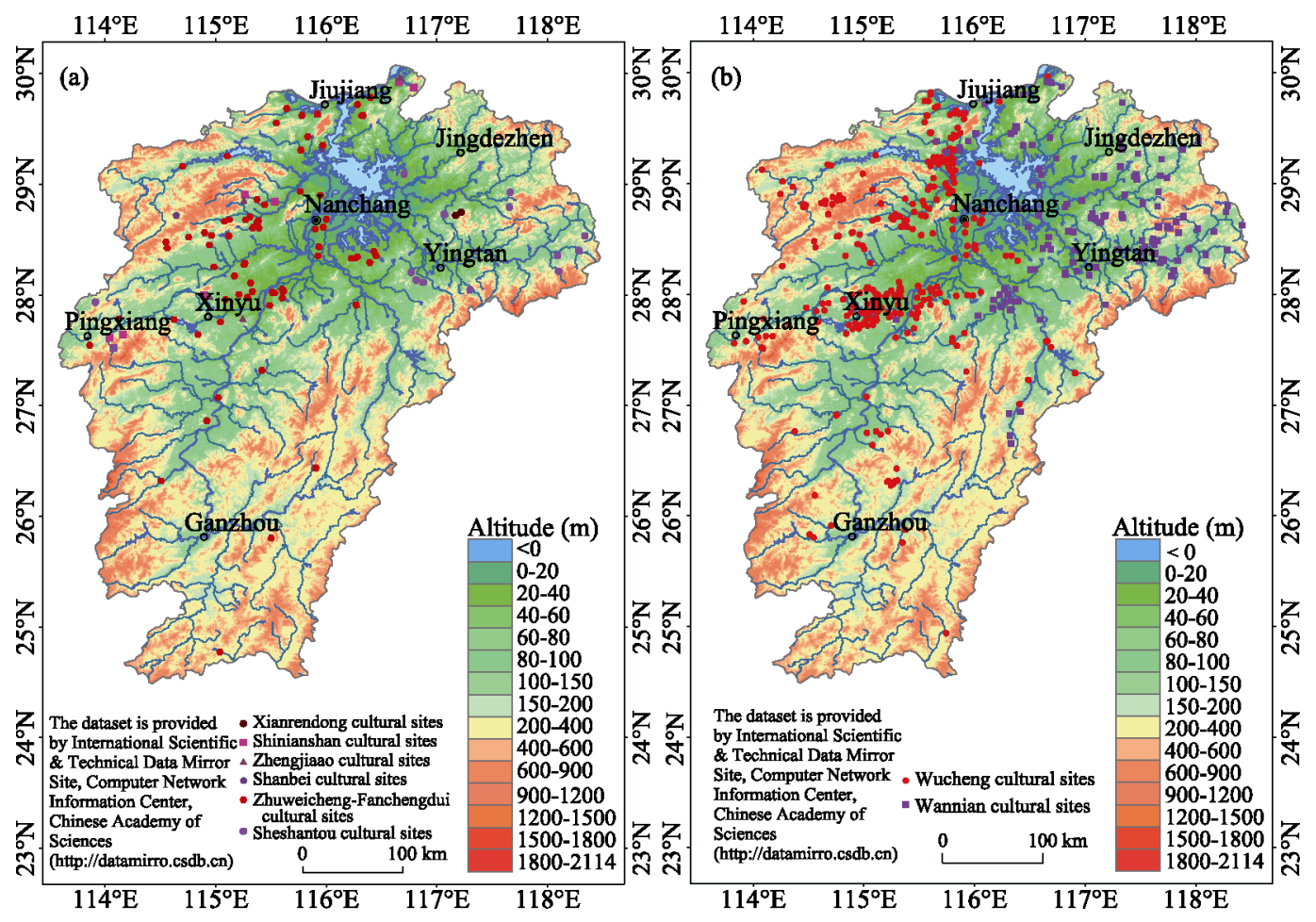

Figure 2 Archaeological sites of the Poyang Lake Basin: (a) in the Neolithic period (10.0-3.6 ka BP) and (b) in the Shang and Zhou dynasties (3.6-2.8 ka BP)

\section{Results}

\subsection{Distribution of archaeological sites at different elevations}

Distribution of archaeological sites at various elevations is presented in Table 2. Sites of the Xianrendong culture (early Neolithic culture) were concentrated in the areas with elevations of 50-200 m. At the stage of the middle Neolithic culture, approximately $43.7 \%$ of the sites were distributed in areas with elevation of 50-200 m, and $31.3 \%$ at the elevations lower than $50 \mathrm{~m}$, the other $25 \%$ at the elevations of $200-500 \mathrm{~m}$. At the period of the Late Neolithic cultures, $40.2 \%$ of the sites were distributed at elevations lower than $50 \mathrm{~m}, 52.2 \%$ at elevations between 50 and $200 \mathrm{~m}$, and only 7.6\% (seven sites) in areas above $200 \mathrm{~m}$ in elevation. These implied that the number and density of sites at the stage of late Neolithic cultures increased substantially, and more of them were located at lower elevations, compared with the stage of the middle Neolithic culture. Generally, at the stage of the Neolithic culture, $38.1 \%$ of the sites were located in areas with an elevation lower than $50 \mathrm{~m}, 51.8 \%$ of the sites were located at the elevations between 50 and $200 \mathrm{~m}$, and $10 \%$ of the sites were located at elevations above $200 \mathrm{~m}$. During the period of the Shang and Zhou dynasties, the number of sites in areas with an elevation lower than $50 \mathrm{~m}$ increased to $228(46.8 \%) ; 212$ sites $(43.5 \%)$ and 47 sites $(9.7 \%)$ were located at elevations between 50 and $200 \mathrm{~m}$ and at elevations higher than 200 m, respectively. From the Neolithic Age to Shang and Zhou dynasties, more and more sites moved from the high altitude hilly environment to the low altitude of river terraces and flood plains. 
Table 2 Altitude distribution of the Neolithic and Shang-Zhou cultural sites in the Poyang Lake Basin

\begin{tabular}{lcccc}
\hline \multicolumn{1}{c}{ Cultural type } & Total & $<50 \mathrm{~m}$ & $50-200 \mathrm{~m}$ & $200-500 \mathrm{~m}$ \\
\hline Xianrendong & 2 & 0 & 2 & 0 \\
Shinianshan & 8 & 2 & 2 & 4 \\
Zhengjia'ao & 6 & 2 & 4 & 0 \\
Shanbei & 2 & 1 & 1 & 0 \\
Zhuweicheng-Fanchengdui & 78 & 35 & 41 & 5 \\
Sheshantou & 14 & 2 & 7 & 37 \\
Wucheng & 342 & 171 & 78 & 10 \\
Wannian & 145 & 57 & 78 & 5 \\
\hline
\end{tabular}

\subsection{Temporal-spatial variations of archaeological sites}

\subsubsection{Early Neolithic Age (10.0-8.0 ka BP)}

Only two early Neolithic sites, which belonged to the Xianrendong culture, have been discovered and excavated, i.e., the Diaotonghuan site and Xianrenrong site (Peng and Zhou, 2004), both located in the little intermontane basin southeast of the Poyang Lake (Figure 2a). The Xianrendong culture, with chipped and polished stone and sandy pottery, was the earliest Neolithic culture of the Poyang Lake Basin, and it was typical of cave culture in southern China (Peng, 1981a, 1981b). These two neighbouring sites are situated $1 \mathrm{~km}$ away from each other. One site (Xianrendong) is located at the foot of a limestone hill $35 \mathrm{~m}$ away from a small stream and $3 \mathrm{~m}$ higher than its present usual water surface. The other site (Diaotonghuan) is located at the top of a small hill $30 \mathrm{~m}$ high and above the previously mentioned stream. The sites were probably located here and selected for settlements by ancient people due to convenient water taking and flood avoiding (Guo and Li, 1963; Zhao, 2000). Many animal bones, snails, mussels, fish bones, and other remains excavated at the sites demonstrated that hunting and gathering could have been the main production and living styles of ancient people of that time (Zhong, 1996).

\subsubsection{Middle Neolithic Age (8.0-4.8 ka BP)}

There are eight sites of the Shinianshan culture, six sites of the Zhengjia'ao culture, and two sites of the Shanbei culture in the middle Neolithic period (Figure 2a). The archaeological sites of the Shinianshan culture are sparsely distributed in the west of the Poyang Lake and along the middle and lower reaches of the Ganjiang River area between elevations of 50 and $500 \mathrm{~m}$. During the Shinianshan Age, the production mode gradually changed from gathering, fishing, and hunting to primitive farming (Liu, 1992b). The Zhengjia'ao cultural sites, with distribution similar to the Shinianshan cultural sites, are also sparsely distributed in the west and south of the Poyang Lake. The Zhengjia'ao culture is a subcultural type of the Xuejiagang culture in southern Anhui Province, influenced deeply by the surrounding culture, such as the Qujialing and Songze culture, which gave the Zhengjia'ao culture more local characteristics that differed from its mother culture in Anhui (Peng, 1981a; Zhong and Peng, 2008). Only two sites of the Shanbei culture, a more local culture, were found, both located in the catchment of Xiushui River, west of the Poyang Lake. During this period the 
settlement areas were no longer confined to caves. Some geomorphologic landscape, such as river terraces, foothills and little intermontane basins, were gradually chosen for human inhabitation, suggesting the beginning of the Agrarian Revolution in the Poyang Lake Basin.

\subsubsection{Late Neolithic Age (4.8-3.6 ka BP)}

Seventy-eight sites of Zhuweicheng-Fanchengdui culture and 14 sites of Sheshantou culture of the late Neolithic period were excavated (Figure 2a). The Zhuweicheng-Fanchengdui cultural sites were widely distributed on flood plains around Poyang Lake and in the middle and lower reaches of the Ganjiang River, Fuhe River and Xiushui River. The concentrate area of the Zhuweicheng-Fanchengdui culture was situated in the middle and lower reaches of the Ganjiang River and the lower reaches of Xiushui River, bordering Poyang Lake to the west and north. At the same time, another regional culture, called the Sheshantou culture, had been developing sites to the northeast and east of Poyang Lake and showed similar geographic distribution as the Zhuweicheng-Fanchengdui cultural sites. Many types of complicated stone and ceramic tools, and various edible plants indicated a more developed stage of regional cultures (Peng, 1981a; Zhong and Peng, 2008).

\subsubsection{Shang and Zhou dynasties (3.6-2.8 ka BP)}

There are 487 sites of Shang and Zhou dynasties excavated in the Poyang Lake Basin (Figure 2b) belonging to Wucheng culture and Wannian culture. Many of the sites were inherited from the Zhuweicheng-Fanchengdui culture. Wucheng culture was the most widely distributed pre-historic culture in the Poyang Lake Basin, and the number of sites found at present is 342. The sites are distributed at the west and southwest of Poyang Lake with two centres of location, one on the southwestern beach of the Poyang Lake and the other in the Xinyu region between the Ganjiang River and Xinjiang River (Figure 2b). Additionally, 145 sites of Wannian culture of Shang and Zhou dynasties were found on the eastern flood plains of the Poyang Lake, indicating a similar geographic distribution as Wucheng culture. Wannian culture was contiguous with the bronze culture, such as Zhejiang's High Altar, Shanghai's Maqiao culture, and Huangtulun culture (Zhong and Peng, 2008). Wucheng culture, represented by the Wucheng site, was one of the most advanced bronze cultures in South China (Peng, 1981a; Zhong and Peng, 2008).

\subsection{Subsistence models of regional culture}

\subsubsection{Characteristics of production artefacts}

Production tools are relevant to the way humans lived and could be used to determine the mode of economics. Many utensils were excavated from the Xianrendong, Shinianshan, Zhuweicheng, and Wucheng sites (Table 3) (Guo and Li, 1963; JPICRA., 1991; Li and Yu, 1976; Li et al., 1982; Zhou et al., 1993; Peng and Li, 1975; JPICRA., 1995; Peng et al., 1991).

Table 3 shows that the amount of fishing and hunting tools was much larger than agricultural productive tools in the early Neolithic period, demonstrating that fishing and gathering (paddy gathering included) were the main context of economic production. During the middle Neolithic period, the amount of agricultural production tools increased significantly, while fishing and hunting tools increased simultaneously, indicating a mixed mode of production of farming, fishing and hunting. The amount of production tools declined in the late 
Neolithic period for a few excavated sites, but the amount of farming and domestic tools increased more than the amount of fishing and hunting tools, indicating that agriculture was the dominant type of production. A large quantity of spinning tools was unearthed in the middle-late Neolithic era, showing that the textile and handicraft industry had been created and was a very important part of the life at that time. Meanwhile, dings, cups, and pot tools increased substantially, revealing a more extensive community life than previously. During the Shang and Zhou dynasties, a diversity of tools for farming were developed, suggesting extensive farming activities, which implied farming was probably the primary production activity, while fishing and hunting activities were also important ways of production.

Table 3 Production and living tools unearthed at typical sites in the Poyang Lake Basin (Guo and Li, 1963; Liu and Li, 1991; Li and Yu, 1976; Li et al., 1982; Zhou et al., 1993; Peng and Li, 1975; JPICRA, 1995; Peng et al., 1991)

\begin{tabular}{|c|c|c|c|c|c|}
\hline Type & Shapes & $\begin{array}{l}\text { Early Neolithic } \\
\text { period }\end{array}$ & $\begin{array}{c}\text { Middle } \\
\text { Neolithic period }\end{array}$ & $\begin{array}{l}\text { Late Neolithic } \\
\text { period }\end{array}$ & $\begin{array}{c}\text { Shang and } \\
\text { Zhou dynasties }\end{array}$ \\
\hline \multirow{13}{*}{$\begin{array}{l}\text { Agricultural } \\
\text { tools }\end{array}$} & Celt & 1 & 4 & 1 & 21 \\
\hline & Tapered pike & 8 & & 1 & 12 \\
\hline & Stepped adze & 2 & 90 & 15 & 13 \\
\hline & Stone axe & & 17 & 17 & 39 \\
\hline & Hoe & & 2 & & \\
\hline & Drill & & 4 & 2 & 1 \\
\hline & Shovel & & 2 & 24 & 2 \\
\hline & Knife & & 19 & 11 & 70 \\
\hline & Millstone & & & 3 & \\
\hline & Dagger-axe & & & & 33 \\
\hline & Sickle & & & & 7 \\
\hline & Stone mould & & & & 9 \\
\hline & Plough & & & & 2 \\
\hline \multirow{8}{*}{$\begin{array}{l}\text { Fishing and } \\
\text { hunting tools }\end{array}$} & Osteotome & 1 & & & \\
\hline & Fish fork & 1 & & & \\
\hline & Arrowhead & 3 & 83 & 48 & 138 \\
\hline & Hole puncher & 40 & 19 & & \\
\hline & Burr & 6 & 183 & & 10 \\
\hline & Spear & & 4 & & 37 \\
\hline & Net & & 1 & 2 & 43 \\
\hline & Pie tools & & 9 & & \\
\hline \multirow{8}{*}{ Life tools } & Bone needle & 7 & & & \\
\hline & Bone awl & 27 & & & \\
\hline & Frotton & & 2 & 1 & \\
\hline & Ding & & 134 & 281 & 32 \\
\hline & Cup & & 97 & 12 & 31 \\
\hline & Pot & & 4 & 11 & 61 \\
\hline & Spinning wheel & & 37 & 27 & 23 \\
\hline & Cooking tripod & & & & 125 \\
\hline
\end{tabular}




\subsubsection{Agricultural development}

The early Neolithic sites had remains of paddies, indicating that this area might be one of the origins of rice agriculture in China (Peng and Zhou, 2004; Zhao, 1998). A large number of agricultural implements, pottery, and a mix of grass and mud, mingled with rice husk and rice straw and dated to 5000 a BP (Table 1), were unearthed at the Shanbei site. These findings suggested that the ancient people lived a sedentary life, relying on primitive farming (Peng, 1981a; Zhong and Peng, 2008). Based on records of starch grains at the Shinianshan, Zhuweicheng, Fanchengdui, Yinjiaping, and Sheshantou sites (Figure 3) (Wan et al., 2012a, 2012b), food composition of the ancient inhabitants in the 5000-3500 a BP was assessed: First, except for the Sheshantou site (4.5-3.5 ka BP), starch grains (Oryza spp., Triticeae, Coix spp., roots and tubers included) were generally common at the Shinianshan, Zhuweicheng, Fanchengdui, and Yinjiaping sites (5.0-4.0 ka BP). Setaria spp. was not found (Figure 3) with the highest proportion of Triticeae and Coix spp., which were the major food source in this period. Second, Rice (Oryza spp.) remains were relatively common in all five sites, indicating rice agriculture had been well developed in the Poyang Lake Basin. During 5000-4000 a BP, the plants utilized were Coix spp., plants from the species Triticeae, Oryza spp., and other species of edible roots and tubers. During 4500-3500 a BP, the ancient people who lived in the region utilized rice (Oryza spp.), millet (Setaria spp.) and some root and tuber crops (Figure 3). Third, species of roots and tubers, accounting for approximately $8 \%$, were found at the five sites, reflecting that these plants may have played a role in social production. Some plants were not identifiable, possibility because of contamination or other various plants uses. Preliminary analysis of carbonized seeds from sites of the Shang and Zhou dynasties showed a crop assemblage of rice and millet (Chen et al., 2015). These results indicate that ancient plant use was diverse in the Poyang Lake Basin.

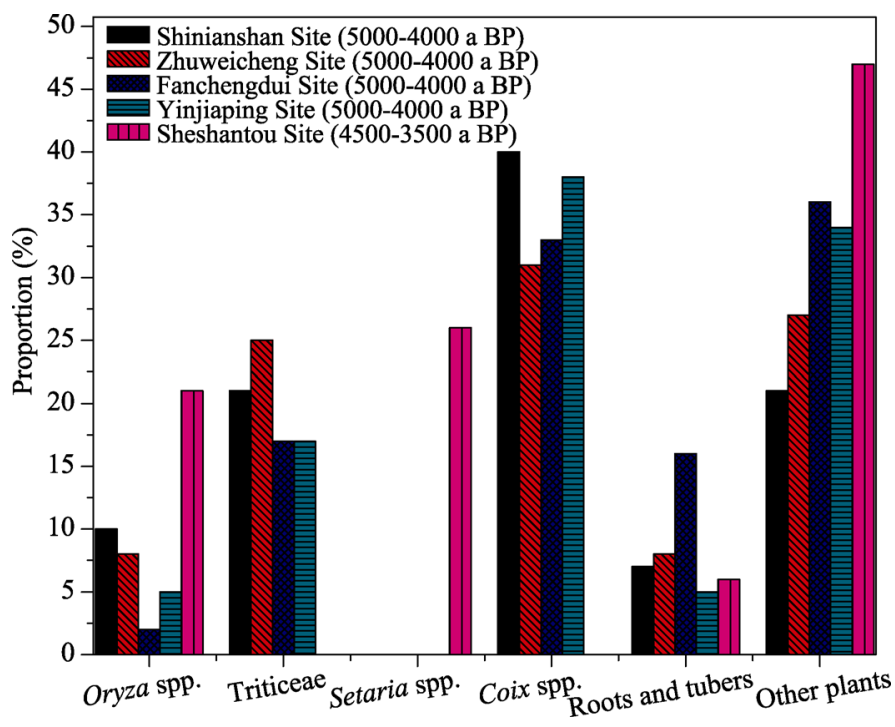

Figure 3 Proportion of each type of starch grain retrieved from the five Neolithic archaeological sites of the Poyang Lake Basin (Wan et al., 2012a, 2012b)

\section{Discussion}

\subsection{Environmental changes during the Holocene in the Poyang Lake Basin}

The available data of the Holocene climate and environmental changes in the study area were few. Therefore, the discussion in this paper is based on previous studies on sediments of Poyang Lake (Ma et al., 2004; Xie and Fan, 2005; Xie et al., 2006), $\delta^{18} \mathrm{O}$ records of sta- 
lagmites collected from the Dongge Cave (Wang et al., 2005) and Shanbao Cave (Shao et al., 2006) in the Yangtze River Basin (Figure 4). These studies can be utilized to reconstruct palaeoenvironmental change of Holocene.

These records indicated that temperature and humidity increased throughout the East Asian monsoon region between 10 and $6 \mathrm{ka}$ BP due to an intensified East Asian monsoon early in the Holocene (Shao et al., 2006). Assembalges of pollen analysis of sediments from core ZK08 in Jiujiang during the period of 8.0-6.0 ka BP were characterized by a high percentage of arboreal pollen, including Liquidambar, Evergreen Quercus, and pollen of ferns, suggesting a warm and humid climate (Xie and Fan, 2005). Subtropical forest was relatively reduced during the period of 6.0-5.0 ka BP, while temperate forests increased with deciduous oak and Castanopsis as species used for construction. An increase of Chenopodiaceae pollen illustrated that a certain amount of drought-resistant plants existed due to climate change to drier conditions (Xie and Fan, 2005). During the period between 5.0-3.6 ka BP, subtropical trees flourished. The main constructive species were Quercus, Castanopsis, deciduous oak, and maple. The $\delta^{13} \mathrm{C}$ values were less negative, and aquatic plant blooms showed enlargement of the area in the Poyang Lake, corresponding to the formation of Poyang Lake similar to today (Jiang and Piperno, 1999; Ma et al., 2004; Xie and Fan, 2005; Xie et al., 2006; Tan, 1982). Between 3.6 and $2.0 \mathrm{ka} \mathrm{BP}$, the $\delta^{18} \mathrm{O}$ value of stalagmites increased, suggesting that the amount of summer monsoon precipitation began to decrease (Wang et al., 2005; Shao et al., 2006). Decreases of subtropical forest in large areas and increases of the Chenopodiaceae and Artemisia indicated that the climate became cool and dry (Xie and Fan, 2005; Xie et al., 2006). In conclusion, the Holocene climate during 10.0-2.8 ka BP experienced three stages: a warm-humid stage at 10.0-6.0 ka BP, a warm-dry stage at 6.0-3.6 ka $\mathrm{BP}$, and a cold-dry stage during the Shang and Zhou dynasties.



Figure 4 Correlation of prehistoric culture phases in the Poyang Lake Basin and the Holocene climate evolution inferred from $\delta^{13} \mathrm{C}$ record from Poyang Lake (ZK01), $\delta^{18} \mathrm{O}$ records of stalagmites from Dongge Cave, percentage of pollen (\%) from Jiujiang (ZK08), Jiangxi Province and $\delta^{18} \mathrm{O}$ records of stalagmites from Shanbao Cave, Hubei Province. 


\subsection{Impacts of climate change on temporal-spatial distribution of archaeological sites}

The early Neolithic Age was a warm and moist stage, and ancient people relied mainly on hunting and gathering activities. As Figure 2a shows, the early Neolithic sites were distributed in the little intermontane basin to the southeast of Poyang Lake, where natural limestone caves provided preferable habitat. Bones of fish, birds, and animals including the mammals Macaca mulatta, Lepus sp., Nyctereutes procyonoides Gray, and Rusa sp. (Huang and $\mathrm{Ji}, 1963$ ) at the Xianrendong site, and phytolith materials of rice (Oryza sativa L.) (Zhao, 2000) at the Diaotonghuan site, identified during archaeological discoveries, demonstrated that forest and swamp environments offer rich biological resources during $10.0-8.0 \mathrm{ka} \mathrm{BP}$ (Huang and Ji, 1963).

The middle Neolithic Age experienced a milder-wetter climate. Many agriculture, manufacturing, and fishing tools were unearthed at the Shinianshan site, suggesting a transition from hunting-gathering to agriculture ( $\mathrm{Liu}$ and $\mathrm{Li}, 1991$ ). The Zhengjia'ao culture, which probably was a sub-type of Xuejiagang culture south of Anhui and mainly located in the hilly areas near the river, demonstrated a pattern of life similar to the Shinianshan culture. During this period, the sites were extensively distributed on river terraces and hilly platforms to the western and northern parts of the Poyang Lake (Figure 2a).

Discovery of more and more farming tools and complex implements during the period of the Zhuweicheng-Fanchengdui culture, verified further development of agricultural production and farming. During this period, more sites were moved to flood plains around the Poyang Lake and into the middle and lower reaches of the Ganjiang River and Xiuhe River, where the number of relatively large scale sites increased (Figure 2a). The Sheshantou cultural sites were mainly distributed in the eastern Poyang Lake area and along the middle and lower Xinjiang River and Raohe River. The sites were mainly distributed around Poyang Lake and were widely distributed in plain areas (Figure 2a). The climate was slightly warm and humid in this period, and the productivity and ability of the people to response to disasters had been improved such that the scope of activities gradually expanded.

Irrigation systems emerged in the Shang and Zhou dynasties, more sites moved to lower flood plains than previously, and Poyang Lake transitioned to the present geographical pattern (Jia, 2016). In addition, rice hulls and drinking vessels indicated that rice cultivation was well-developed and food production was so abundant that there was enough surplus to make alcohol (Liu, 1992a). The flood plains of Poyang Lake and the middle and lower reaches of rivers were the preferred choice as dwelling sites for more peoples, for its large geographical capacity, and for its fertile, silty flood-soil sediments. Expanded population and well developed agricultural technique were likely conducive to exploitation of these flood plains. Moreover, the dry climatic conditions at this time were probably another driving factor, suggesting that under dry conditions, it was difficult for ancient people, living in high landscape to fetch water resource. Consequently, they found it necessary to exploit extensive geographic area for improved survival.

\subsection{Climate change, geographical migration of sites, population, and life pressure during 10.0-2.8 ka BP}

The early Holocene climate is well suited for wild Oryza species (Zhao and Piperno, 2000). 
Wild rice might have been domesticated for food by the ancient people of the Xianrendong site (Cao, 1998), showing that these ancient people were the first group to engage in early rice farming. Paddy grain gathering probably originated from wild fields (Zhao, 1998). Unearthed animal bones showed that young, old, and sick individuals occupy a certain proportion of the population, while domesticated animals were very few. Ancient people mainly relied on hunting and gathering (Huang and Ji, 1963). There was no indication that revolutionizing farming took place in Xianrendong site. Factors contributing to this included rich wild resources for food in that basin and too small a population size to constitute high resource consumption. Thus, at that time, ancient people encountered no living stress.

On the contrary, during the subsequent phases in the middle-late Holocene (6.0-2.8 ka $\mathrm{BP}$ ), the situation changed rapidly and dramatically to a large population size and development of farming implements. Primitive agriculture was combined with fishing and hunting (Table 3). With the change of production modes, a diversity of cultural types developed, along with the expansion of human activities. More farming tools, rice husks and rice traces unearthed from sites of Shanbei culture verified that the regional agrarian revolution had started (Peng, 1982). During the late Neolithic Age, rice (Oryza spp.), Triticeae, Coix spp., millet (Setaria spp.), roots and tubers were found, showing that the ancient diet in the Poyang Lake Basin was highly diverse (Figure 3). Agriculture had become the main mode of livelihood for local residents. The abundance of food enabled people to survive better, and simultaneously to reduce their dependence on natural resources. This is consistent with the evolutionary principle. The quality of production tools, e.g., dagger-axes, sickles, and ploughs, and the number of types of settlements in the Shang and Zhou dynasties, which were greater than in the Neolithic Age (Table 3), indicated that agricultural production had made progress towards technical maturity. The drying climate also played an important role for relocation of residential areas, from river terraces and hilly landscape to floodplains of the Poyang Lake and the middle and lower reaches of the Ganjiang River, Fuhe River, and Xiushui River between the middle Neolithic Age and the Shang and Zhou dynasties era in the Poyang Lake Basin. During the middle-late Holocene, ancient people had to take measures to adapt themselves to new situation and must have done so.

\section{Conclusions}

(1) Between 10.0 and $6.0 \mathrm{ka} \mathrm{BP}$, the Holocene climate in the Poyang Lake Basin was warm and moist, intensified by the East Asian summer monsoon. Relatively dry climatic conditions have gradually prevailed since $6.0 \mathrm{ka}$ BP.

(2) The few discovered archaeological sites of early Neolithic Age are located in intermoutane basins. A large number of archaeological sites of middle-late Neolithic Age and Shang and Zhou dynasties are extensively distributed on river terraces and hilly landscape in the middle and lower reaches of the Ganjiang River, Xiushui River, Fuhe River, and Xinjiang River. Archaeological sites gradually migrated downward to flood plains in the lower reaches of rivers around Poyang Lake in order to exploit these flood plains. Drying climate in the middle-late Holocene help to bring about this process.

(3) Economic cultivation as the origin of farming might have occurred independently in the Poyang Lake Basin. One appeared at the Xianrendong cultural stage. During the late 
Neolithic Age, agricultural tools tended to be complex, and a diversity of plant community was under cultivation. Agriculture was established as the foundation of the production mode and human activity was strengthened. The Shang and Zhou dynasties witnessed that the civilization developed to a certain stage, while agriculture became common and fishing thrived. These developments enriched human activities, and ultimately stimulated the evolution of society.

\section{References}

Cao K P, 1993. Reflect on Fanchengdui Culture. Relics From South, (4): 53-59. (in Chinese)

Cao K P, 1998. Restudy remains of Xianrendong site and renewed sense of rice agriculture origin in China. Southeast Culture, (3): 25-31. (in Chinese)

Chen F H, Dong G H, Zhang D J et al., 2015a. Agriculture facilitated permanent human occupation of the Tibetan Plateau after 3600 B.P. Science, 248-250.

Chen F H, Xu Q H, Chen J H et al., 2015b. East Asian summer monsoon precipitation variability since the last deglaciation. Scientific Reports, 1-11.

Chen J, 2005. Ecological history view of the rise and decline of Liangzhu culture. Southeast Culture, (5): 33-40. (in Chinese)

Chen X X, Zhou G M, Gong W, 2015. A preliminary analysis on the carbonized seeds and fruits from Niucheng Site (2006-2008), Xingan, Jiangxi Province. Jianghan Archaeology, (3): 100-108. (in Chinese)

Duan Y, 2003. Research on the seven decades of Sanxingdui and Bashu Culture. Forum on Chinese Culture, (3): 11-35. (in Chinese)

Evans D J A, England J H, Farge C L et al., 2014. Quaternary geology of the Duck Hawk Bluffs, southwest Banks Island, Arctic Canada: A re-investigation of a critical terrestrial type locality for glacial and interglacial events bordering the Arctic Ocean. Quaternary Science Reviews, 91: 82-123.

Gao C, Wang X Y, Jin G J et al., 2009. Spatial distribution features of archaeological sites on the western shore of the Chaohu Lake, China. Geographical Research, 28(4): 979-989. (in Chinese)

Grahn Y, Mauller P M, Bergamaschi S et al., 2013. Palynology sequence stratigraphy of three Devonian rock units in the Apucarana sub-basin (Parana Basin, south Brazil): Additional data and correlation. Review of Palaeobotany and Palynology, 198: 27-44.

Guo Y W, Li J H, 1963. Excavation briefing of Xianrendong Site in Wannian, Jiangxi. The Chinese Journal of Archaeology, (1): 1-16. (in Chinese)

Guo Y Y, Mo D W, Mao L J et al., 2013. Settlement distribution and its relationship with environmental changes from the Neolithic to Shang-Zhou dynasties in northern Shandong, China. Journal of Geographical Sciences, 23(4): 679-694.

Guo Y Y, Mo D W, Mao L J et al., 2014. Settlement distribution and its relationship with environmental changes from the Paleolithic to Shang-Zhou period in Liyang Plain, China. Quaternary International, 321: 29-36.

Haug G H, Güther D, Peterson L C et al., 2003. Climate and the collapse of Maya civilization. Science, 299: $1731-1735$.

Huang W B, Ji H X, 1963. Note on Holocene Xianrendong cave deposit of Wannian, China. Vertebrata Palasiatica, 7 (3): 263-271. (in Chinese)

Innes J B, Zong Y Q, Wang Z H et al., 2014. Climatic and palaeoecological changes during the mid- to Late Holocene transition in eastern China: High-resolution pollen and non-pollen palynomorph analysis at Pingwang, Yangtze coastal lowlands. Quaternary Science Reviews, 99: 164-175.

Institute of Archaeology, CASS, 1974. Radiocarbon dating report (3). Archaeology, (5): 333-338. (in Chinese)

Institute of Archaeology, CASS, 1977. Radiocarbon dating report (4). Archaeology, (3): 200-204. (in Chinese)

Institute of Archaeology, CASS, 1979. Radiocarbon dating report (6). Archaeology, (1): 89-96. (in Chinese)

Institute of Archaeology, CASS, 1991. Radiocarbon dating report (18). Archaeology, (7): 657-663. (in Chinese) 
Jia Y L, 2016. Environment Evolution of Poyang Lake, in Ecological Security Issues and Monitoring. Beijing: Science Press, 1-18. (in Chinese)

Jiang Q H, Piperno D R, 1999. Environmental and archaeological implications of a Late Quaternary palynological Sequence, Poyang Lake, Southern China. Quaternary Research, 52: 250-258.

Jiangxi Provincial Institute of Cultural Relics and Archaeology (JPICRA), Xiamen University, Xinyu Municipal Museum, 1991. The Shinianshan site at Xinyu city, Jiangxi province. Acta Archaeologia Sinica, (3): $285-323$. (in Chinese)

Jiangxi Provincial Institute of Cultural Relics and Archaeology (JPICRA), Xiamen University, Guangfeng county Cultural Relic Administration, 1997. The third excavation of Sheshantou site in Guangfeng, Jiangxi Province. Relics From South, (1): 1-22. (in Chinese)

Jiangxi Provincial Institute of Cultural Relics and Archaeology (JPICRA), Xiamen University, Zhangshu Museum, 1995. The eighth excavation briefing of Wucheng Site in Zhangshu, Jiangxi. Relics From South, (1): 5-23. (in Chinese)

Jiangxi Provincial Institute of Cultural Relics and Archaeology (JPICRA), Jingan Museum, 1989. The briefing on tomb in Zhengjia'ao site. Southeast Culture, (Suppl.1): 1-13. (in Chinese)

Kuper R, Kropelin S, 2006. Climate-controlled Holocene occupation in the Sahara: Motor of Africa's evolution. Science, 313(5788): 803-807.

Li F, Wu L, Zhu C et al., 2013. Spatial-temporal distribution and geographic context of Neolithic cultural sites in the Hanjiang River Basin, Southern Shaanxi, China. Journal of Archaeological Science, 40 (8): 3141-3152.

Li J H, Liu L, Liu S Z, 1986. Analysis of Zhuweicheng Culture: The late of Neolithic Culture in Jiangxi Province. Jiangxi Historical Relics, (1): 52-62. (in Chinese)

Li J H, Liu S Z, Huang S G, 1986a. Neolithic culture in Jiangxi Province. Jiangxi Historical Relics, (S1): 1-16. (in Chinese)

Li J H, Liu S Z, Huang S G, 1986b. Review of Bronze Culture in Jiangxi Province. Jiangxi Historical Relics, (S1): 31-53. (in Chinese)

Li J T, Wu M J, Zhong L Q et al., 1982. The second excavation briefing of Zhuweicheng Site in Zhangshu, Jiangxi. Archaeology, (2): 130-138. (in Chinese)

Li K F, Zhu C, Jiang F Q et al., 2014. Archaeological sites distribution and its physical environmental settings between ca 260-2.2 ka BP in Guizhou, Southwest China. Journal of Geographical Sciences, 24 (3): 526-538.

Li K Y, 1982. Characteristic of Neolithic culture in Jiangxi province. Jiangxi Historical Relics, (1): 76-85. (in Chinese)

Li Y S, Yu J D, 1976. Excavation briefing of Zhuweicheng site in Zhangshu, Jiangxi. Archaeology, (6): 383-391. (in Chinese)

Li Z X, Zhu C, Wu G X et al., 2013. Spatial and temporal distribution of prehistoric human sites and its driving factors in Henan Province. Acta Geographica Sinica, 68(11): 1527-1737. (in Chinese)

Liu Q R, 1992a. Agricultural of Jiangxi in Shang and Zhou dynasties. Agricultural Archaeology, (3): 100-103. (in Chinese)

Liu S Z, 1992b. Cultural analysis of Shinianshan site. Relics From South, (3): 52-59. (in Chinese)

Liu S Z, 1993. Discuss of Neolithic culture in Jiangxi Province. Archaeology, (12): 1099-1109. (in Chinese)

Liu S Z, 2000. Retrospect and prospects of Jiangxi Province archaeology. Archaeology, (12): 24-34. (in Chinese)

Liu Z Y, Wen X Y, Brady E C et al., 2014. Chinese cave records and the East Asian summer monsoon. Quaternary Science Reviews, 83: 115-128.

Long Q, Bai J, Ju Y, 1992. Discover and Research from Shang Dynasty culture in the Jiangxi Province. Southeast Culture, (Suppl.1): 82-92. (in Chinese)

Ma Z X, Huang J H, Wei Y et al., 2004. Organic carbon isotope records of the Poyang Lake sediments and their implications for the paleoclimate during the last $8 \mathrm{ka}$. Geochimica, 33(3): 279-285. (in Chinese)

Mayle F E, Iriarte J, 2014. Integrated palaeoecology and archaeology: A powerful approach for understanding pre-Columbian Amazonia. Journal of Archaeological Science, 51: 54-64. 
Oinonen M, Pesonen P, Alenius T et al., 2014. Event reconstruction through Bayesian chronology: Massive mid-Holocene lake-burst triggered large-scale ecological and cultural change. The Holocene, 24(11): 1419-1427.

Oonk S, Spijker J, 2015. A supervised machine-learning approach towards geochemical predictive modelling in archaeology. Journal of Archaeological Science, 59: 80-88.

Peng S F, 1981a. Neolithic culture in Jiangxi Province. Journal of Nanchang University (Social Science), (4): 95-108. (in Chinese)

Peng S F, 1981b. Questions about Xianrendong Culture from the early Neolithic in Southern of China. Jiangxi Historical Relics, (2): 9-18. (in Chinese)

Peng S F, 1982. Research of Shanbei Culture, Jiangxi. Archaeology, (1): 40-47. (in Chinese)

Peng S F, Li J H, 1975. Excavation briefing of Wucheng site in Zhangshu, Jiangxi. Cultural Relics, (7): 51-71. (in Chinese)

Peng S F, Liu L, Zhan K X, 1991. Excavation briefing of Dayangzhou site in Xingan, Jiangxi. Cultural Relics, (10): 1-26. (in Chinese)

Peng S F, Zhou G M, 2004. Xianrendong site and Diaotonghuan site of Jiangxi: Case study research from Paleolithic to Neolithic. Agricultural Archaeology, (3): 29-39. (in Chinese)

Peng Y G, 2004. A study of Wucheng Culture [D]. Chengdu: Sichuan University. (in Chinese)

Qiu S R, Qiu X C, 2006. Jiangxi general situation and localism and dialect culture. Jiangxi Linguistics Society Collected Papers, 4-9. (in Chinese)

Shao X H, Wang Y J, Cheng H et al., 2006. Long-term trend and abrupt events of the Holocene Asian monsoon interred from a stalagmite $\delta^{18} \mathrm{O}$ record from Shennongjia in Central China. Chinese Science Bulletin, 51(2): 221-228.

Sun L, Gao M H, 2006. The geographical landscape of Majiabang culture. Huaxia Archaeology, (3): 40-45. (in Chinese)

Tan Q X, Zhang X G, 1982. Course of history in Poyang Lake. Fudan Journal (Social Sciences Edition), (2): 42-51. (in Chinese)

Tang S L, 1996. Discussion on the Zhuweicheng Culture. Relics From South, (2): 56-66. (in Chinese)

Wan Z W, Yang X Y, Ge Q S et al., 2012a. Plant resource utilization at Sheshantou Site in Jiangxi Province based on starch grain analysis. Progress in Geography, 31(5): 639-645. (in Chinese)

Wan Z W, Yang X Y, Ge Q S et al., 2012b. Starch grain analysis reveals Late Neolithic plant utilization in the middle reaches of the Ganjiang River. Scientia Sinica (Terrae), 42(10): 1582-1589. (in Chinese)

Wang Y J, Cheng H, Edwards R L et al., 2005. The Holocene Asian Monsoon: Links to solar changes and North Atlantic climate. Science, 308: 854-857.

Wu C L, Zhang Y, Li Q et al., 2011. An environmental database and temporal and spatial distribution of Chinese paleoanthropological sites. Chinese Science Bulletin, 56(26): 2229-2231. (in Chinese)

Wu L, Li F, Zhu C et al., 2012. Holocene environmental change and archaeology, Yangtze River Valley, China: Review and prospects. Geoscience Frontiers, 3(6): 875-892.

Wu L, Zhu C, Zheng C G et al., 2014a. Holocene environmental change and its impacts on human settlement in the Shanghai area, East China. Catena, 114: 78-89.

Wu L, Zhu C, Zheng C G et al., 2014b. Impact of Holocene climate change on the prehistoric cultures of Zhejiang region, East China. Journal of Geographical Sciences, 24(4): 669-688.

Wu R, Deng Z Q, Zhang Z G et al., 2005. Scientific and technological research of the unearthed pottery from the Neolithic Xianrendong site in Wannian County, Jiangxi Province. Archaeology, (7): 62-69. (in Chinese)

Xiao Y T, 1991. Exploration of Neolithic culture in Jiangxi Province. Relics From Jiangxi, (2): 44-50. (in Chinese)

Xie S C, Evershed R P, Huang X Y et al., 2013. Concordant monsoon-driven postglacial hydrological changes in peat and stalagmite records and their impacts on prehistoric cultures in central China. Geology, 41(8): $827-830$. 
Xie Z D, Fan S X, 2005. Sporopollen record of hole ZK08 in Jiujiang, Jiangxi, and paleoenvironmental information reflected by it. Geological Bulletin of China, 24(2): 170-175. (in Chinese)

Xie Z D, Feng S H, Huang W H et al., 2006. Sporopollen record of drilling hole ZK01 and its paleoenvironmental information in Poyang Lake area Jiangxi. Resources Survey \& Environment, 27(1): 60-69. (in Chinese)

Xu C Q, 1996. The study of divide into different period in Shinianshan site. Relics From South, (2): 49-55. (in Chinese)

Xu Q H, Li M Y, Zhang S R et al., 2015. Modern pollen processes of China: Progress and problems. Scientia Sinica (Terrae), 45: 1661-1682. (in Chinese)

Xu Z F, 1987. Wucheng site and Shang Culture in Jiangxi Province. Jianghan Archaeology, (3): 47-50. (in Chinese)

Zhang J R, Jia Y L, Lai Z P et al., 2011. Holocene evolution of Huangqihai Lake in semi-arid northern China based on sedimentology and luminescence dating. The Holocene, 21(8): 1261-1268.

Zhang P, Miao Y F, Zhang Z Y et al., 2013. Late Cenozoic sporopollen records in the Yangtze River Delta, East China and implications for East Asian summer monsoon evolution. Palaeogeography, Palaeoclimatology, Palaeoecology, 388: 153-165.

Zhao D S, 2009. On the era, development stages and the related issues of Wannian Culture. Southeast Culture, (2): 36-47. (in Chinese)

Zhao Z J, 1998. The middle Yangtze region in China is one place where rice was domesticated: Phytolith evidence from the Diaotonghuan cave, northern Jiangxi. Antiquity, 72 (278): 885-897.

Zhao Z J, 2000. Research phytolith of oryza in Diaotonghuan site. Agricultural Archaeology, (3): 68-69. (in Chinese)

Zhao Z J, Piperno D R, 2000. Late Pleistocene/Holocene environments in the middle Yangtze River Valley, China and rice (Oryze sativa L.) domestication: The phytolith evidence. Geoarchaeology, 15(2): 203-222.

Zheng C G, Zhu C, Zhong Y S et al., 2008. Relationship between the temporal-spatial distribution of archaeological sites and natural environment from the Paleolithic Age to the Tang and Song dynasties in the Three Gorges Reservoir of Chongqing area. Chinese Science Bulletin, 53(S1): 107-128.

Zhong L Q, 1996. The two problems of Xianrendong culture in Jiangxi Province. In: Wu M J, Wu C M (eds.), the Southeast Archaeological Research (section 1). Xiamen: Xiamen University Press, 38-42. (in Chinese)

Zhong L Q, 2007. Comparative study of the late Neolithic cultures in Minjing River valley and the Ganjing-Poyanghu region. Archaeology, (9): 57-66. (in Chinese)

Zhong Q H, Peng S F, 2008. General History of Jiangxi Province, Pre-Qin volume. Nanchang: Jiangxi People's Publishing House, 40-111. (in Chinese)

Zhou G M, Zeng Q, Liu L, 1993. The seventh excavation briefing of Wucheng Site in Zhangshu, Jiangxi. Cultural Relics, (7): 1-9. (in Chinese)

Zhu C, Wu L, Li L et al., 2014. Research progress on Holocene environmental archaeology in the Yangtze River Valley, China. Acta Geographica Sinica, 69(9): 1268-1283. (in Chinese)

Zhu C, Zheng C G, Ma C M et al., 2005. Identifying paleoflood deposits archived in Zhongba Site, the Three Gorges Reservoir region of the Yangtze River, China. Chinese Science Bulletin, 50(21): 2493-2504.

Zhu C, Zhong Y S, Zheng C G et al., 2007. Relationship of archaeological sites distribution and environment from Paleolithic Age to the Warring States Time in Hubei Province. Acta Geographica Sinica, 62(3): $227-242$. (in Chinese)

Zhu G Y, Zhu C, Ling S J et al., 2005a. Spatial-temporal distribution of Neolithic and Xia-Shang-Zhou dynasties sites and relationship between human and environment in Anhui Province. Scientia Geographica Sinica, 25(3): 346-352. (in Chinese) 